\title{
Characterisation of Physicochemical Properties of Propionylated Corn Starch and Its Application as Stabiliser
}

\author{
Lee-Fen Hong', Lai-Hoong Cheng ${ }^{2}$, Chong Yew Lee ${ }^{1}$ and Kok Khiang Peh ${ }^{1 *}$ \\ ${ }^{1}$ School of Pharmaceutical Sciences, Universiti Sains Malaysia, USM, 11800 Minden, Penang, Malaysia \\ ${ }^{2}$ Food Technology Division, School of Industrial Technology, Universiti Sains Malaysia, USM, \\ 11800 Minden, Penang, Malaysia \\ Received: September 20, 2014 \\ Accepted: May 13, 2015
}

\begin{abstract}
Summary
A series of propionylated starches with different degrees of substitution (DS) was synthesised and their physicochemical properties and application as a stabiliser were investigated. Starch propionates with moderate DS were prepared by esterification of native corn starch with propionic anhydride. By varying the reaction times of the esterification process, twelve starch propionates with DS of 0.47 to 0.94 were prepared. FTIR and NMR confirmed the introduction of propionyl groups to the starch. X-ray diffraction pattern showed reduced crystallinity in the starch propionates. The contact angle was found to increase proportionately with the increase in DS. Swelling power results showed that starch propionates were able to swell more than native corn starch at low temperature $\left(40{ }^{\circ} \mathrm{C}\right)$. Oil-in-water $(\mathrm{O} / \mathrm{W})$ emulsions prepared using starch propionates (DS of 0.64 to 0.86 ) showed exceptional stability when challenged by centrifugation stress test. These stable $\mathrm{O} / \mathrm{W}$ emulsions had viscosities in the range of $1236.7-3330.0 \mathrm{mPa} \cdot \mathrm{s}$. In conclusion, moderately substituted short-chain (propionylated) starches could be a promising cold swelling starch, thickener and $\mathrm{O} / \mathrm{W}$ emulsion stabiliser in food, pharmaceutical and cosmetic industries.
\end{abstract}

Key words: starch propionate, degree of substitution, physicochemical properties, oil-in-water emulsion, stabiliser

\section{Introduction}

Plenty of work has been done to expand the usefulness and versatility of starch as a property-enhancing material in food. Modification of starch by means of esterification provides ample opportunities to alter the physicochemical properties of macromolecules. Starch esters exhibit unique properties, namely lower gelatinization temperature, lower retrogradation and lower tendency to form gels (1) as well as enhanced hydrophobic properties $(2,3)$ when compared to the native counterpart. These unique properties make starch esters suitable for use in refrigerated and frozen foods and as an emulsion stabiliser and encapsulating agent. Two common starch esters used in foods are acetylated starch and octenyl succinic (OS) starch. Acetylated starch is prepared with short-chain (C2) while octenyl succinylated starch with medium-chain (C12) fatty acids. Owing to the different fatty acid chain lengths, acetylated and OS starch showed different properties, especially emulsion stabilising and encapsulating properties. Comparatively, OS starch showed much better emulsion stabilising and encapsulating properties when compared to acetylated starch (4).

From a nutritional point of view, acylated starch appeared to be resistant $(3,5)$. The nondigestible starch fraction was found to be able to reduce postprandial blood glucose and insulin concentration (6), which helps to 
maintain a healthy glycemic profile. Annison et al. (5) reported that acylated starch survived intestinal passage and produced short-chain fatty acids from bacterial fermentation in the large bowel. The reduction of colonic $\mathrm{pH}$ by short-chain fatty acids was found to promote colonic health $(7,8)$. In vitro or in vivo studies also showed that different short-chain fatty acid profiles were produced when different resistant starch ester was used. Ferguson and Jones (9) conducted an in vitro fermentation on OS starch and showed that it released the highest amount of butyric acid among other short-chain fatty acids. The release of propionate was found to be interesting as it has been linked to the reduction of cholesterol in serum and liver in rats (10). Animal study revealed that propionate released in caecal digesta was $95.6 \mu \mathrm{mol}$ from starch propionate, $41.2 \mu \mathrm{mol}$ from starch acetate, $36.3 \mu \mathrm{mol}$ from starch butyrate and $12.1 \mu \mathrm{mol}$ from control starch (5).

Despite the health benefits of starch propionate, not much study, however, has been conducted on the characterisation of moderately substituted starch propionate. In this paper, we present a simple method to prepare starch propionate using propionic anhydride and sodium hydroxide as catalyst. Physicochemical properties of starch propionates were then characterised. The potential of starch propionates as a stabiliser was also evaluated.

\section{Materials and Methods}

\section{Raw materials}

Native corn starch $(20.2 \%$ amylose and $79.8 \%$ amylopectin) was purchased from Zhucheng Xingmao Corn Developing Company (Shandong, PR China). Propionate anhydride was obtained from Merck (Kenilworth, NJ, USA). Olive pomace oil was purchased from Basso Fedele and Figli Srl (San Michele di Serino, AV, Italy). Ethanol, $99.7 \%$, was purchased from QRëC (Chonburi, Thailand). Iodine and potassium iodide were obtained from Sigma-Aldrich (St. Louis, MO, USA). All other reagents used were of analytical reagent grade.

\section{Preparation of starch propionate using alkaline catalyst}

A mass of $140 \mathrm{~g}$ of corn starch $(0.864 \mathrm{~mol}$ of anhydroglucose unit) was stirred with $674.8 \mathrm{~g}(5.185 \mathrm{~mol})$ of propionic anhydride in 2-litre Schott bottle for $5 \mathrm{~min}$ in a water bath maintained at $30{ }^{\circ} \mathrm{C}$. The catalyst, $50 \%$ (by mass per volume) of sodium hydroxide solution was added to the mixture using biuret at the rate of $0.25-0.33 \mathrm{~mL} / \mathrm{min}$. A mass of $0.15 \mathrm{~g}$ of sodium hydroxide solution, $50 \%$ (by mass per volume), was added per each $g$ of starch. The starch suspension was then transferred to a water bath controlled at $70{ }^{\circ} \mathrm{C}$ and stirred for $12 \mathrm{~h}$ using hotplate (Thermo Fisher Scientific, Waltham, MA, USA). A sample of $67.9 \mathrm{~mL}$ was drawn hourly over a reaction time of $12 \mathrm{~h}$. The sample was added to water ( 3 times volume) to terminate the chemical reaction and centrifuged at $2000 \times g$ for $5 \mathrm{~min}$. The supernatant was discarded and the sediment was washed with 4.5 volumes of water 16 times until reaching $\mathrm{pH}=5.0-5.5$ (SevenEasy $\mathrm{pH}$ meter, Mettler Toledo, Columbus, OH, USA) and conductivity below 2.0 $\mu \mathrm{S} / \mathrm{cm}$ (sensION+ EC5 portable conductivity meter, Hach, Loveland, CO, USA). The starch propionate was dried in an oven at $40{ }^{\circ} \mathrm{C}$ for $48 \mathrm{~h}$. After drying, starch propionate was ground manually and sieved through a $250-\mu \mathrm{m}$ diameter sieve. Starch propionate samples collected hourly over a period of $12 \mathrm{~h}$ were coded as SP1-SP12.

\section{Determination of the degree of substitution}

Degree of substitution (DS) was determined using the method reported by Bhandari and Singhal (11). A mass of $1 \mathrm{~g}$ of native corn starch or starch propionate was accurately weighed into $50 \mathrm{~mL}$ of $75 \%$ (by volume) ethanol solution and stirred at $60 \mathrm{rpm}$ on a hotplate for $30 \mathrm{~min}$ at $50{ }^{\circ} \mathrm{C}$. The starch slurry was then cooled to room temperature $\left(30^{\circ} \mathrm{C}\right)$ and mixed with $40 \mathrm{~mL}$ of $0.5 \mathrm{M} \mathrm{NaOH}$ at $60 \mathrm{rpm}$ using hotplate for $2 \mathrm{~min}$. After mixing, the starch slurry was placed in an orbital shaker at $40 \mathrm{rpm}$ and $30^{\circ} \mathrm{C}$ for $72 \mathrm{~h}$. Phenolphtalein indicator was dropped to the starch slurry and excess of alkali was back titrated with $0.5 \mathrm{M}$ of hydrochloric acid. Native corn starch was treated in the same manner to obtain blank value. The propionyl content and DS were calculated using the equations proposed by Xia et al. (12). The propionyl content (in \%) was calculated using the following equation:

$$
\begin{gathered}
w \text { (propionyl })= \\
=\frac{(V(\text { blank })-V(\text { sample })) \cdot c(\mathrm{HCl}) \cdot 57 \cdot 10^{-3}}{m(\text { sample })} \cdot 100
\end{gathered}
$$

where $V$ is titration volume in $\mathrm{mL}, m$ is mass in $\mathrm{g}, c$ is concentration in $\mathrm{mol} / \mathrm{L}, 57$ is the formula mass of propionyl group and $10^{-3}$ is a factor of conversion of $\mathrm{mL}$ to $\mathrm{L}$.

The degree of substitution (DS) was defined as the average number of sites per $\alpha$-D-glucose unit that possesses a substituent group, and it was calculated as follows:

$$
\mathrm{DS}=\frac{180 \cdot 0.9 \cdot w(\text { propionyl })}{57 \cdot 100-(57-1) \cdot w(\text { propionyl })}
$$

where 180 is the molecular mass of $\alpha$-D-glucose, 0.9 is the stoichiometric constant for conversion of glucose to starch, 57 is the formula mass of propionyl group, and 1 is the atomic mass of hydrogen.

\section{Fourier transform infrared spectroscopy}

The Fourier transform infrared (FTIR) spectra were obtained with a BIO-RAD FTS 3000 IR Spectrum Scanner (BioRad Laboratories, Hercules, CA, USA).

\section{Nuclear magnetic resonance}

The nuclear magnetic resonance (NMR) spectra were recorded using an Ascend 500 spectrometer (Bruker, Ettlingen, Germany) operating at $500 \mathrm{MHz}$ for ${ }^{1} \mathrm{H}$ NMR. 2D $\mathrm{H}-\mathrm{H}$ NMR measurement was conducted to obtain the detailed information on the structure of starch propionate. Native corn starch and starch propionates of $7 \mathrm{mg}$ each were dissolved in $0.7 \mathrm{~mL}$ of deuterated dimethyl sulphoxide (DMSO) with gentle stirring for $6 \mathrm{~h}$ at room temperature to obtain clear solutions.

\section{Powder diffraction}

X-ray patterns of native corn starch and starch propionate powders with different DS values were analyzed 
between $2 \theta=4$ and $45^{\circ}$ using a D8 Advance X-ray diffractometer (Bruker, Berlin, Germany) with $\mathrm{Cu}-\mathrm{K} \alpha$ radiation at a voltage of $40 \mathrm{kV}$ and $40 \mathrm{~mA}$.

\section{Measurement of contact angle}

Contact angle measurement was performed using a Theta Lite optical tensiometer (Attension, Espoo, Finland). Attension Theta software was used to control the drop volume and measure the contact angle. The drop volume of water was fixed at $30 \mu \mathrm{L}$. Sample preparation was carried out according to the method described by Thielemans et al. (13) with slight modifications. Starch pellet was prepared by compressing native corn starch or starch propionate under a pressure of $170.9 \mathrm{~kg} /\left(\mathrm{m} \cdot \mathrm{s}^{2}\right)$ using a hydraulic bench top laboratory press (Carver, Wabash, IL, USA).

\section{Swelling power and percentage of leaching}

Swelling power and percentage of leaching were measured according to the method described by Bordenave et al. (14) with slight modifications. A mass of native corn starch and starch propionate of $0.1 \mathrm{~g}\left(m_{1}\right)$ was weighed separately and put into $1.5-\mathrm{mL}$ microcentrifuge tube. A volume of $1.0 \mathrm{~mL}$ of distilled water was added and the starch suspension was vortexed with vortex mixer (Labnet International Inc., Edison, NJ, USA) followed by heating at 40 or $90^{\circ} \mathrm{C}$ for $5 \mathrm{~min}$.

After that, the tubes were cooled to room temperature for $30 \mathrm{~min}$ and subsequently centrifuged at $14000 \times \mathrm{g}$ for 5 min (1-15 Microfuge, Sigma Laborzentrifugen $\mathrm{GmbH}$, Osterode am Harz, Germany). After centrifugation, the supernatant in the tubes was transferred into a moist dish and the swelled starch precipitate was weighed $\left(m_{2}\right)$. The precipitate and the supernatant were dried separately in an oven at $100{ }^{\circ} \mathrm{C}$ for $20 \mathrm{~h}$. The dried supernatant was weighed and labelled $m_{3}$, while dried precipitate was weighed and labelled $m_{4}$.

The swelling power was calculated as follows:

$$
\text { Swelling power }=m_{2} / m_{4}
$$

and the percentage of leaching was calculated with the following equation:

$$
\text { Percentage of leaching }=m_{3} / m_{1} \cdot 100
$$

\section{Preparation of oil-in-water emulsions}

Olive oil (20\%, by mass) and water ( $80 \%$, by mass) were weighed separately. Starch propionate at $15 \%$ (by mass) based on aqueous phase was weighed. Starch propionate was mixed with water and oil. The emulsion was homogenized using an Ultra Turrax T25 homogenizer (IKA Labortechnik, Staufen, Germany) at a speed of $4838.4 \times g$ for $5 \mathrm{~min}$. A control emulsion was prepared using native corn starch.

\section{Centrifugation stress study}

The oil-in-water $(\mathrm{O} / \mathrm{W})$ emulsions were centrifuged at $4000 \times g$ for $30 \mathrm{~min}$ (Heraeus Multifuge X1, Thermo Fisher Scientific). The emulsion stability (ES) parameter pro- posed by Taherian et al. (15) was used to evaluate the stability of the emulsion. The ES was calculated as follows:

$$
\mathrm{ES}=h_{\mathrm{t}} / h_{\mathrm{s}} \cdot 100
$$

where $h_{\mathrm{t}}$ is the total height of emulsion and $h_{\mathrm{s}}$ is the height of sediment layer. Stable O/W emulsion has ES value of $100 \%$.

\section{Measurement of emulsion viscosity}

The viscosity of the emulsion was measured using an SV-10 Sine-wave Vibro Viscometer (A\&D, Tokyo, Japan). The emulsion sample was placed in a plastic sample cup and viscosity was measured at $30^{\circ} \mathrm{C}$.

\section{Statistical analysis}

The results are presented as mean values \pm standard deviation (S.D.). The results were analysed using one-way analysis of variance (SPSS software, v. 13.0 for Windows; SPSS Inc., Chicago, IL, USA). When there was a statistically significant difference $(\mathrm{p}<0.05)$, Duncan's post-hoc test was performed.

\section{Results and Discussion}

\section{Effect of reaction time on the degree of substitution of starch propionates}

Fig. 1 shows that when corn starch was treated with propionic anhydride for a period of $12 \mathrm{~h}$, the degree of substitution (DS) increased steadily with reaction time. The range of DS values of starch propionates was between 0.47 and 0.94 . This trend may be attributed to an increase in diffusion of acylating reagent into and adsorption onto starch molecules with prolonged reaction time (16). Besides, the progressive increase in DS with time could be partly attributed to alkaline treatment. In the presence of alkali, protons of the hydroxyl groups may dissociate, leaving negative charges on starch molecules. The negatively charged starch molecules may then repel each other causing dissociation of the double helices of amylopectin (17), which leads to the exposure of more reactive sites on the macromolecule for the acylating reagent to react upon.

$\mathrm{Xu}$ et al. (18) synthesised starch acetate with a DS of approx. 1.6, at $0.15 \mathrm{~g}$ of $\mathrm{NaOH}$ per $\mathrm{g}$ of starch, reaction

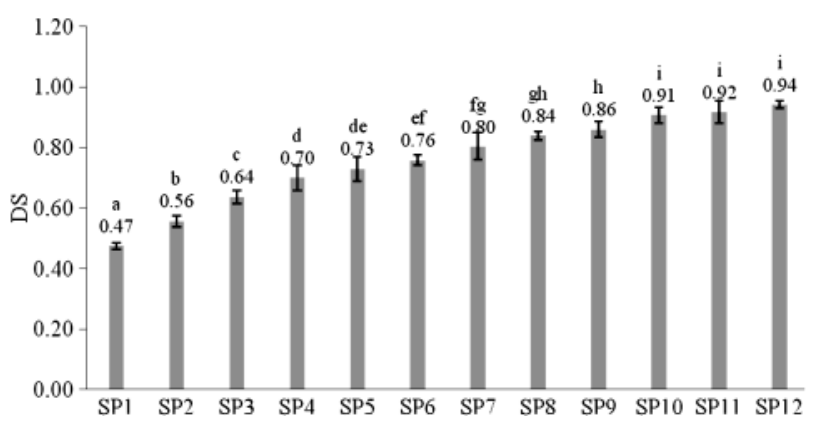

Fig. 1. Degree of substitution (DS) of various starch propionates (SP) prepared over a period of $12 \mathrm{~h}$. Values with different letters are significantly different $(\mathrm{p}<0.05)$ 
temperature of $123^{\circ} \mathrm{C}$, reaction time of $60 \mathrm{~min}$, and starch/ acetic anhydride mass ratio of 1:4. In contrast, the present study produced starch propionate with DS values of $0.47-$ 0.94 , which are considered moderate, at a condition of $0.15 \mathrm{~g}$ of $\mathrm{NaOH}$ per $\mathrm{g}$ of starch, reaction temperature of 70 ${ }^{\circ} \mathrm{C}$, reaction time of $1-12 \mathrm{~h}$, and starch/propionic anhydride mass ratio of 1:4.82. Differences in the substitution degree of acylated starches could be due to differences in reaction conditions such as temperature and type of anhydride. Increasing temperature produced starch with higher DS, indicating that higher temperature favoured acceleration of the forward reaction $(19,20)$. In the present study, starch propionate with lower DS was obtained because a lower reaction temperature was used. Other authors showed that acyl anhydride with longer chain lengths of fatty acids tends to form starch ester with lower DS $(20,21)$. The reaction occurred at slower rate due to the steric effects of larger molecular size of reagent and a lower diffusion rate in the starch matrix.

The common practice to prepare propionylated starch is to use propionic anhydride. Various catalysts have been used such as 1-methylimidazole (5), sodium hydroxide (18), formamide (22) and pyridine (23). The selection of catalyst was based on its suitability and safety in the preparation of starch propionate as food, cosmetic and pharmaceutical additives. Sodium hydroxide was chosen as catalyst since it is water soluble and can be easily washed off after the esterification process.

\section{Fourier transform infrared spectroscopy of native starch and starch propionates}

FTIR spectra of native corn starch and starch propionates SP1, SP6 and SP12 are presented in Fig. 2. Absorption bands at 3423.51, 2928.17, 1650.13 and 1239.09 corresponded to hydrogen-bonded hydroxyl, $\mathrm{CH}_{2}$ symmetrical stretching vibrations, scissoring of two $\mathrm{OH}$ bonds of absorbed water molecules and $\mathrm{C}-\mathrm{O}-\mathrm{H}$ deformation, respectively $(12,24,25)$.

All starch propionates gave a new peak at 1743.48 $\mathrm{cm}^{-1}$, indicating stretching of ester carbonyl $\mathrm{C}=\mathrm{O}(12,18,23)$ and successful propionylation. Two new bands were also seen at 2878.26 and $2986.96 \mathrm{~cm}^{-1}$ in the spectra indicating

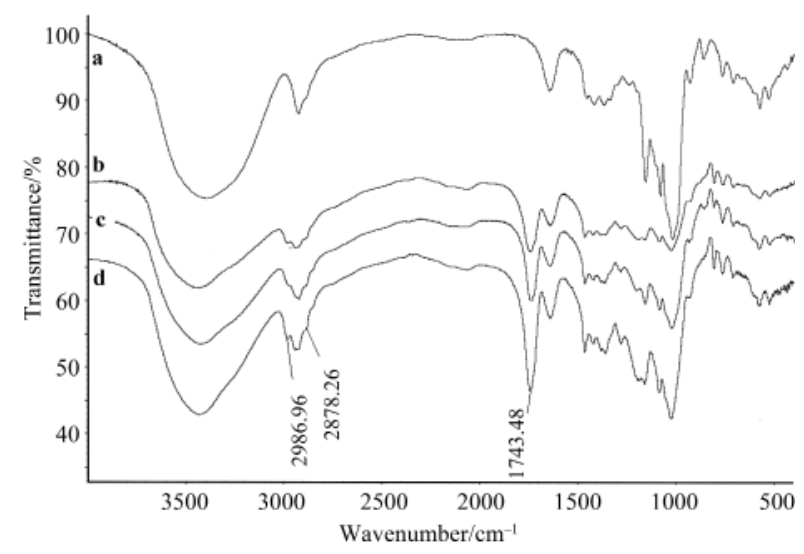

Fig. 2. FTIR spectra of: native corn starch (a), SP1 (DS=0.47) (b), SP6 (DS=0.76) (c) and SP12 (DS=0.94) (d). DS=degree of substitution, $\mathrm{SP}=$ starch propionate methyl and methylene $\mathrm{C}-\mathrm{H}$ stretching of propionyl groups in esterified starch $(24,26,27)$.

\section{Nuclear magnetic resonance spectroscopy of native starch and starch propionate}

The ${ }^{1} \mathrm{H}$ NMR spectra of native starch and starch propionate SP12 (DS=0.94) are shown in Fig. 3. For native starch, ${ }^{1} \mathrm{H}$-chemical shift at $5.4963 \mathrm{ppm}$ was assigned to $\mathrm{OH}-3$, at $5.3985 \mathrm{ppm}$ to $\mathrm{OH}-2$, at $5.1051 \mathrm{ppm}$ to $\mathrm{H}-1$, at 4.5731 ppm to $\mathrm{OH}-6$, at 3.6518 ppm to $\mathrm{H}-3$ and at 3.5843 ppm to H-5 $(2,28,29)$. After propionylation, all starch samples exhibited characteristic peaks similar to native starch. The new ${ }^{1} \mathrm{H}$-chemical shifts were observed at 2.3470 and $1.0324 \mathrm{ppm}$, corresponding to $\mathrm{CH}_{2}$ and $\mathrm{CH}_{3}$ protons, respectively (30). These observations indicated a successful propionylation. This result was also corroborated by the two new bands evident at 2878.26 and $2986.96 \mathrm{~cm}^{-1}$ in the FTIR spectra, indicating methyl and methylene $\mathrm{C}-\mathrm{H}$ stretching of propionyl groups in starch propionate. This shows that propionylation possibly occurred at $\mathrm{OH}-2$, $\mathrm{OH}-3$ and $\mathrm{OH}-6$ of the anhydroglucose units.

a)
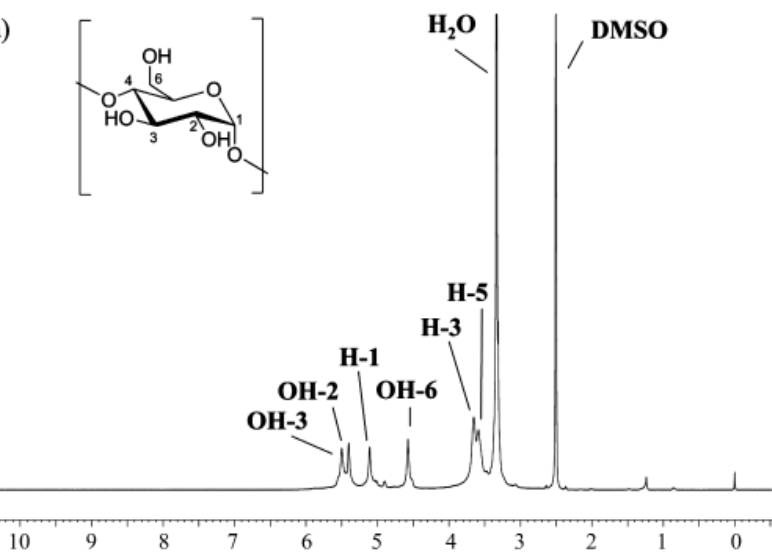

9

8

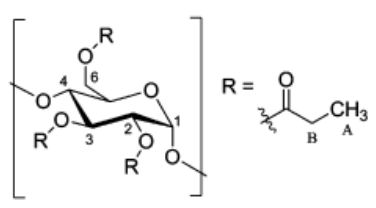

OH-3 OH-2

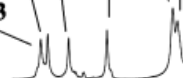

4

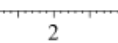

0

b)

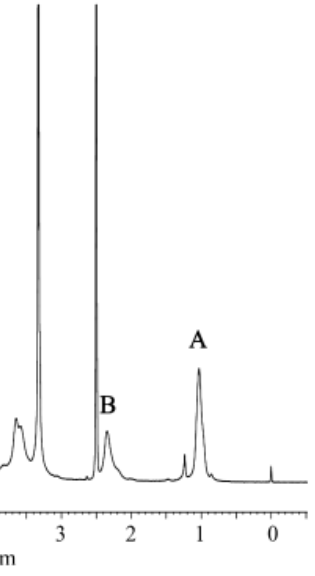

Fig. 3. ${ }^{1} \mathrm{H}$ NMR spectra of: a) native corn starch and b) SP12 (DS=0.94). $\mathrm{SP}=$ starch propionate, $\mathrm{DS}=$ degree of substitution

\section{Crystalline patterns of native starch and starch propionates}

Fig. 4 shows the powder diffraction patterns of native starch, SP1 (DS=0.47), SP6 (DS=0.76) and SP12 (DS=0.94). 


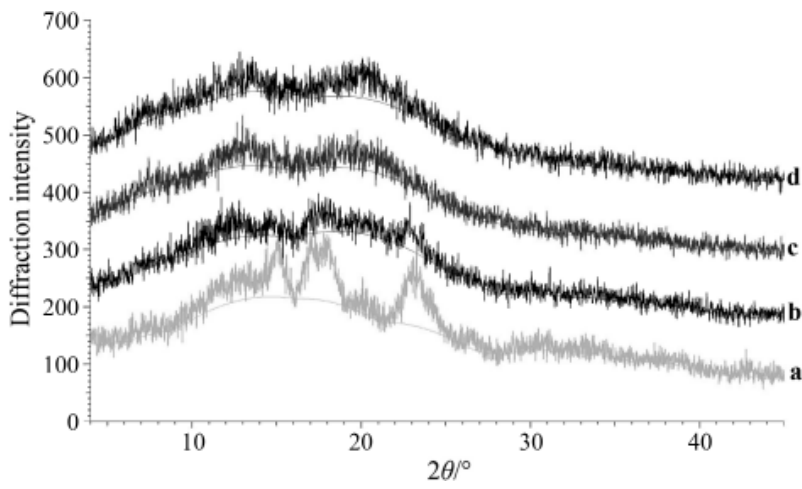

Fig. 4. Powder $X$-ray patterns of: native corn starch (a), SP1 $(\mathrm{DS}=0.47)(\mathrm{b}), \mathrm{SP} 6(\mathrm{DS}=0.76)(\mathrm{c})$ and SP12 (DS=0.94) (d). DS=degree of substitution, $\mathrm{SP}=$ starch propionate

Native corn starch showed an A pattern with strong diffraction peaks at $2 \theta$ of 15.22 , and unresolved doublet at $17.08,18.02$ and 23.29 (2). The crystallinity of starch was formed by the double helices of amylopectin chains $(31,32)$. According to $\mathrm{Xu}$ et al. (18), the intra- and intermolecular hydrogen bonds account for highly ordered crystalline structure in starch granule. The peak intensities of SP1 were found to be lower than the characteristic peaks of the native corn starch. Only part of the hydroxyl groups was replaced with propionyl group. The remaining hydroxyl groups may still form hydrogen bonds, resulting in the decrease of diffraction peak intensities in SP1 (18). Further propionylation caused progressive changes in the X-ray diffraction patterns as shown by the formation of broad peaks in SP6 and SP12. These changes indicated the disruption of starch granule crystallinity through the replacement of the hydroxyl groups with propionyl groups on the starch molecules upon esterification $(2,18)$.

\section{Effect of propionylation on the hydrophobicity of starch}

Table 1 shows contact angle values of various starch propionates. It is evident that the contact angle values progressively increased with propionylation time. The gradual increase in contact angle from samples SP1-SP11 was due to an increase in the hydrophobicity which was
Table 1. Contact angle $(\theta)$ values of the prepared various starch propionates

\begin{tabular}{ll}
\hline Sample (DS value) & \multicolumn{1}{c}{$\theta /^{\circ}$} \\
\hline SP1 $(0.47)$ & $(70.9 \pm 1.9)^{\mathrm{a}}$ \\
SP3 $(0.64)$ & $(73.6 \pm 1.9)^{\mathrm{b}}$ \\
SP5 $(0.73)$ & $(76.1 \pm 1.7)^{\mathrm{c}}$ \\
SP7 $(0.80)$ & $(79.6 \pm 2.3)^{\mathrm{d}}$ \\
SP9 $(0.86)$ & $(81.2 \pm 2.3)^{\mathrm{de}}$ \\
SP11 $(0.92)$ & $(82.2 \pm 1.7)^{\mathrm{e}}$ \\
\hline
\end{tabular}

Data are presented as mean values \pm standard deviations of six independent replicates. Values in the same column with different letters in superscript differ significantly $(p<0.05)$. $\mathrm{DS}=$ degree of substitution, $\mathrm{SP}=$ starch propionate

caused by propionylation of the starch. It can be deduced that in the process of propionylation, hydrophilic hydroxyls were substituted with more hydrophobic ester groups. The same observation was reported by Chi et al. (2). Contact angle value of native corn starch was not measured because when water was dropped onto the surface of the pellet, it quickly disintegrated. It was concluded that native corn starch is too hydrophilic for the measurement of contact angle.

\section{Effect of propionylation on the swelling and leaching behaviour of starch}

Table 2 shows swelling power values of native corn starch and various starch propionates. Native corn starch exhibited swelling power of 2.3 and $10.9 \mathrm{~g} / \mathrm{g}$ at incubation temperatures of 40 and $90{ }^{\circ} \mathrm{C}$, respectively. At $40{ }^{\circ} \mathrm{C}, 0.4 \%$ of starch polymers leached out of native corn starch. Leaching increased to $1.6 \%$ when native corn starch was incubated at $90{ }^{\circ} \mathrm{C}$. As shown by Bordenave et al. (14), native corn starch showed a swelling power of $7.84 \mathrm{~g} / \mathrm{g}$ and leaching of $1.72 \%$ when the experiment was conducted at $23{ }^{\circ} \mathrm{C}$ for $30 \mathrm{~min}$. Native corn starch has been reported to exhibit swelling power of about $12.81 \mathrm{~g} / \mathrm{g}$ and leaching $>5$ $\%$ when the starch was incubated at $90{ }^{\circ} \mathrm{C}$ for $1 \mathrm{~h}$ (33). In the present study, native corn starch had much lower swelling power and percentage of leaching, which was probably due to the short incubation period of $5 \mathrm{~min}$.

Table 2. Swelling power and percentage of leaching of native corn starch and various starch propionates at different incubation temperatures

\begin{tabular}{|c|c|c|c|c|}
\hline \multirow{3}{*}{ Sample (DS value) } & \multicolumn{4}{|c|}{ Temperature $/{ }^{\circ} \mathrm{C}$} \\
\hline & \multicolumn{2}{|c|}{40} & \multicolumn{2}{|c|}{90} \\
\hline & Swelling power/(g/g) & Leaching/\% & Swelling power/(g/g) & Leaching/\% \\
\hline Native (0.00) & $(2.3 \pm 0.1)^{\mathrm{a}}$ & $(0.4 \pm 0.1)^{\mathrm{a}}$ & $(10.9 \pm 0.2)^{\mathrm{f}}$ & $(1.6 \pm 0.1)^{\mathrm{a}}$ \\
\hline SP1 (0.47) & $(5.1 \pm 0.1)^{\mathrm{b}}$ & $(1.9 \pm 0.2)^{\mathrm{b}}$ & $(9.97 \pm 0.09)^{\mathrm{e}}$ & $(5.6 \pm 0.9)^{\mathrm{b}}$ \\
\hline SP3 (0.64) & $(6.79 \pm 0.08)^{\mathrm{f}}$ & $(2.4 \pm 0.3)^{\mathrm{b}}$ & $(8.4 \pm 0.3)^{\mathrm{d}}$ & $(5.1 \pm 1.0)^{\mathrm{b}}$ \\
\hline SP5 (0.73) & $(6.8 \pm 0.2)^{\mathrm{f}}$ & $(4.2 \pm 0.9)^{\mathrm{c}}$ & $(7.5 \pm 0.2)^{\mathrm{c}}$ & $(5.8 \pm 1.0)^{\mathrm{b}}$ \\
\hline SP7 (0.80) & $(6.45 \pm 0.01)^{\mathrm{e}}$ & $(5.6 \pm 1.1)^{\mathrm{cd}}$ & $(7.06 \pm 0.04)^{\mathrm{b}}$ & $(5.9 \pm 0.6)^{\mathrm{b}}$ \\
\hline SP9 (0.86) & $(5.7 \pm 0.1)^{\mathrm{d}}$ & $(5.8 \pm 0.7)^{\mathrm{d}}$ & $(6.3 \pm 0.2)^{\mathrm{a}}$ & $(6.0 \pm 0.7)^{\mathrm{b}}$ \\
\hline SP11 (0.92) & $(5.5 \pm 0.2)^{c}$ & $(5.7 \pm 0.7)^{\mathrm{cd}}$ & $(6.1 \pm 0.2)^{\mathrm{a}}$ & $(5.9 \pm 0.9)^{\mathrm{b}}$ \\
\hline
\end{tabular}

Data are presented as mean values \pm standard deviations of three independent replicates. Values in the same column with different letters in superscript differ significantly $(\mathrm{p}<0.05)$. $\mathrm{DS}=$ degree of substitution, $\mathrm{SP}=$ starch propionate 
After propionylation, corn starch showed a higher swelling power compared to native corn starch at incubation temperature of $40^{\circ} \mathrm{C}$. According to some authors, acylation could weaken the intermolecular hydrogen bonding within starch granule, making it readily swollen when heated at a lower temperature (34). It was observed that swelling power and percentage of leaching of starch propionates increased from SP1 (DS=0.47) to SP5 (DS=0.73). The weak intermolecular hydrogen bonding present within starch propionate was substantiated by the X-ray patterns seen in Fig. 4. On the other hand, from SP5 $(\mathrm{DS}=0.73)$ to SP11 (DS=0.92) swelling power decreased but percentage of leaching reached plateau because of the enhanced hydrophobicity of starch propionates when more and more hydroxyl groups were replaced by propionyl groups.

At $90{ }^{\circ} \mathrm{C}$, a lower swelling power was evident in starch propionates when compared with native corn starch. Native corn starch with intact granules can swell to its maximum when heated in water. Starch propionates having hydroxyl groups replaced with propionyl groups became more hydrophobic than native corn starch, thus resulting in a lower degree of swelling. Swelling power of starch propionates decreased significantly from SP1 (DS=0.47) to SP9 (DS=0.86), but there was no significant difference between SP9 (DS=0.86) and SP11 (DS=0.92). The weakened granular structure of starch propionates contributed to a significantly higher percentage of leaching than the native corn starch. The increase in percentage of leaching in starch propionates from SP1 (DS=0.47) to SP11 (DS=0.92) was not significantly different. The findings showed that percentage of leaching was independent of DS and not significantly affected by the degree of propionylation.

The ability of starch propionate to swell and thicken at low and high temperatures shows that it has the potential for use as a cold swelling starch and thickener.

\section{Physical stability of emulsions with starch propionates}

In a preliminary study, emulsions were prepared with 10, 15 and $20 \%$ (by mass) of starch propionates (SP1-SP12). Emulsions prepared with $10 \%$ of starch propionates separated immediately after centrifugation. At $15 \%$ of starch propionates, O/W emulsions prepared with SP3-SP9 (DS=0.64-0.86) were stable while others separated. At $20 \%$ of starch propionates, emulsions were stable. Hence, $15 \%$ of starch propionate was selected for the study as this fraction could discern the effect of DS of starch propionates on the stability of $\mathrm{O} / \mathrm{W}$ emulsions. Stability of emulsions prepared with $15 \%$ of starch propionate at different DS is shown in Fig. 5. Emulsions were best stabilised with starch propionates SP3-SP9 (DS=0.640.86). A control emulsion was prepared using native corn starch. When emulsion was prepared with native corn starch granules at $15 \%$, it separated quickly after homogenization. The good emulsion stabilising properties of starch propionate indicated that it is better compared to starch acetate. Starch acetate is not known to be a good emulsion stabiliser (4). Thus, the starch propionate produced in the present study could be a promising emulsion stabiliser.

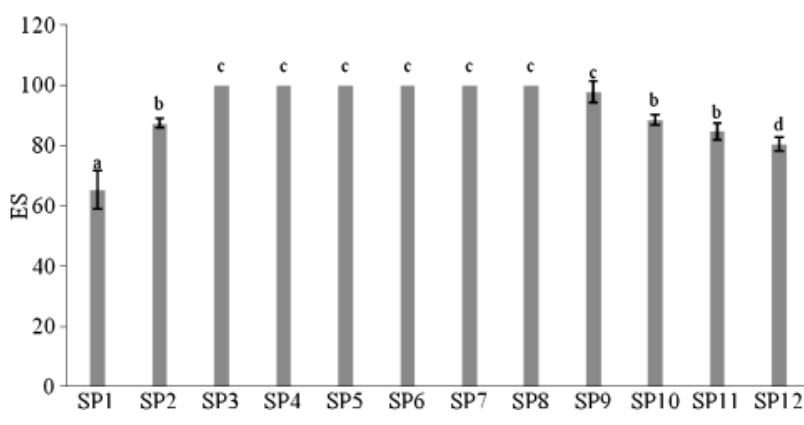

Fig. 5. Emulsion stability (ES) of various oil-in-water emulsions prepared with different degrees of substitution of starch propionates (SP). Values with different letters are significantly different $(\mathrm{p}<0.05)$

\section{Viscosity of emulsions with starch propionates}

The viscosity of emulsions prepared with starch propionates at different DS levels is shown in Table 3. There is an increase in the viscosity of the emulsion from SP1 (DS=0.47) to SP5 (DS=0.73), followed by a decrease after SP5. These changes could be due to the swelling of the starch propionate granules as shown in Table 2. Crosbie (35) reported that viscosity of starch was correlated with its swelling power.

Table 3. Viscosities of oil-in-water emulsions $(\eta)$ prepared with different degrees of substitution (DS) of starch propionates (SP)

\begin{tabular}{lc}
\hline Sample (DS value) & $\eta /(\mathrm{mPa} \cdot \mathrm{s})$ \\
\hline SP1 $(0.47)$ & $(179.4 \pm 25.1)^{\mathrm{a}}$ \\
SP3 $(0.64)$ & $(2990.0 \pm 325.1)^{\mathrm{e}}$ \\
SP5 $(0.73)$ & $(3330.0 \pm 294.6)^{\mathrm{f}}$ \\
SP7 $(0.80)$ & $(1886.7 \pm 119.3)^{\mathrm{d}}$ \\
SP9 $(0.86)$ & $(1236.7 \pm 56.9)^{\mathrm{c}}$ \\
SP11 $(0.92)$ & $(565.3 \pm 51.0)^{\mathrm{b}}$ \\
\hline
\end{tabular}

Data are presented as mean values \pm standard deviations of three independent replicates. Values in the same column having different letters in superscript differ significantly $(\mathrm{p}<0.05)$

The present study found that SP3-SP9 (DS=0.64-0.86) produced stable emulsions with viscosities in the range of 1236.7-3330.0 $\mathrm{mPa} \cdot \mathrm{s}$. On the other hand, SP1 (DS=0.47) and SP11 (DS=0.92) produced unstable O/W emulsions with viscosities in the range of $179.4-565.3 \mathrm{mPa} \cdot \mathrm{s}$. This means that starch propionate with DS between 0.64 and 0.86 can cause sufficient viscosity to stabilise emulsions.

According to McClements (36), in order to be an effective emulsifier, biopolymers must rapidly adsorb to the surface of the oil droplets during homogenization and provide a membrane to prevent aggregation of oil droplets. All biopolymers are capable of providing physical barrier via thickening ability to prevent droplets from getting sufficiently close together to coalesce. Hence, in the present study, the mechanism of emulsion stabilisation was due to viscosity enhancement caused by starch propionate, which prevented the oil droplets from coming close together. 


\section{Conclusions}

In conclusion, starch propionates with degree of substitution (DS) values of $0.47-0.94$ were produced throughout a 12-hour propionylation process. Contact angle values were found to increase proportionately with an increase in DS values, indicating increasing hydrophobicity of the starch propionate. Samples SP1-SP11 showed higher swelling power than the native corn starch at 40 ${ }^{\circ} \mathrm{C}$, indicating cold swelling and thickening properties. Swelling power was found to decrease with increasing DS. Stable oil-in-water $(\mathrm{O} / \mathrm{W})$ emulsions were produced at DS values of $0.64-0.86$ and viscosities between 1236.7 and $3330.0 \mathrm{mPa} \cdot \mathrm{s}$. This shows that starch propionate with the above characteristics has a great potential to be used as a cold swelling starch, thickener as well as $\mathrm{O} / \mathrm{W}$ emulsion stabiliser in food, pharmaceutical and cosmetic industries.

\section{Acknowledgements}

This study is funded by Postgraduate Research Grant Scheme (1001/PFARMASI/846066). The authors would like to thank Institute of Postgraduate Studies, Universiti Sains Malaysia for providing fellowship.

\section{References}

1. Singh J, Kaur L, McCarthy OJ. Factors influencing the physico-chemical, morphological, thermal and rheological properties of some chemically modified starches for food applications - a review. Food Hydrocolloid. 2007;21:1-22. http://dx.doi.org/10.1016/j.foodhyd.2006.02.006

2. Chi H, Xu K, Wu X, Chen Q, Xue D, Song C, et al. Effect of acetylation on the properties of corn starch. Food Chem. 2008;106:923-8.

http://dx.doi.org/10.1016/j.foodchem.2007.07.002

3. Sweedman MC, Tizzotti MJ, Schäfer C, Gilbert RG. Structure and physicochemical properties of octenyl succinic anhydride modified starches: a review. Carbohydr Polym. 2013; 92:905-20. http://dx.doi.org/10.1016/j.carbpol.2012.09.040

4. Murúa-Pagola B, Beristain-Guevara CI, Martínez-Bustos F. Preparation of starch derivatives using reactive extrusion and evaluation of modified starches as shell materials for encapsulation of flavoring agents by spray drying. J Food Eng. 2009;91:380-6.

http://dx.doi.org/10.1016/j.jfoodeng.2008.09.035

5. Annison G, Illman RJ, Topping DL. Acetylated, propionylated or butyrylated starches raise large bowel short-chain fatty acids preferentially when fed to rats. J Nutr. 2003;133:3523-8.

6. Bird AR, Lopez-Rubio A, Shrestha A, Gidley MJ. Resistant starch in vitro and in vivo: factors determining yield, structure, and physiological relevance. In: Kasapis S, Norton IT, Ubbink JB, editors. Modern biopolymer science. London, UK: Academic Press; 2009. pp. 449-510.

7. Englyst HN, Kingman SM, Cummings JH. Classification and measurement of nutritionally important starch fractions. Eur J Clin Nutr. 1992;46:S33-50.

8. Haralampu SG. Resistant starch - a review of the physical properties and biological impact of $\mathrm{RS}_{3}$. Carbohydr Polym. 2000;41:285-92.

http://dx.doi.org/10.1016/S0144-8617(99)00147-2

9. Ferguson MJ, Jones GP. Production of short-chain fatty acids following in vitro fermentation of saccharides, saccharide esters, fructo-oligosaccharides, starches, modified starches and non-starch polysaccharides. J Sci Food Agr. 2000;80:166-70. http://dx.doi.org/10.1002/(SICI)1097-0010(20000101)80:1<166: :AID-JSFA512>3.0.CO;2-K

10. Cheng HH, Lai MH. Fermentation of resistant rice starch produces propionate reducing serum and hepatic cholesterol in rats. J Nutr. 2000;130:1991-5.

11. Bhandari PN, Singhal RS. Studies on the optimisation of preparation of succinate derivatives from corn and amaranth starches. Carbohydr Polym. 2002;47:277-83.

http://dx.doi.org/10.1016/S0144-8617(01)00202-8

12. Xia L, Wenyuan G, Qianqian J, Luqi H, Changxiao L. Study on the morphology, crystalline structure, and thermal properties of Fritillaria ussuriensis Maxim. starch acetates with different degrees of substitution. Starch. 2011;63:24-31. http://dx.doi.org/10.1002/star.201000055

13. Thielemans W, Belgacem MN, Dufresne A. Starch nanocrystals with large chain surface modifications. Langmuir. 2006; 22:4804-10. http://dx.doi.org/10.1021/la053394m

14. Bordenave N, Janaswamy S, Yao Y. Influence of glucan structure on the swelling and leaching properties of starch microparticles. Carbohydr Polym. 2014;103:234-43. http://dx.doi.org/10.1016/j.carbpol.2013.11.031

15. Taherian AR, Fustier P, Ramaswamy HS. Effect of added oil and modified starch on rheological properties, droplet size distribution, opacity and stability of beverage cloud emulsions. J Food Eng. 2006;77:687-96. http://dx.doi.org/10.1016/j.jfoodeng.2005.06.073

16. Khalil MI, Hashem A, Hebeish A. Preparation and characterization of starch acetate. Starch. 1995;47:394-8. http://dx.doi.org/10.1002/star.19950471005

17. Chen J, Jane J. Properties of granular cold-water-soluble starches prepared by alcoholic-alkaline treatments. Cereal Chem. 1994;71:623-6.

18. Xu Y, Miladinov V, Hanna MA. Synthesis and characterization of starch acetates with high substitution. Cereal Chem. 2004;81:735-40.

19. Junistia L, Sugih AK, Manurung R, Picchioni F, Janssen LPBM, Heeres HJ. Experimental and modelling studies on the synthesis and properties of higher fatty esters of corn starch. Starch. 2009;61:69-80. http://dx.doi.org/10.1002/star.200800076

20. Muljana H, van der Knoop S, Keijzer D, Picchioni F, Janssen LPBM, Heeres HJ. Synthesis of fatty acid starch esters in supercritical carbon dioxide. Carbohydr Polym. 2010;82:346-54. http://dx.doi.org/10.1016/j.carbpol.2010.04.067

21. Junistia L, Sugih AK, Manurung R, Picchioni F, Janssen LPBM, Heeres HJ. Synthesis of higher fatty acid starch esters using vinyl laurate and stearate as reactants. Starch. 2008; 60:667-75. http://dx.doi.org/10.1002/star.200800025

22. Rivard C, Moens L, Roberts K, Brigham J, Kelley S. Starch esters as biodegradable plastics: effects of ester group chain length and degree of substitution on anaerobic biodegradation. Enzyme Microb Tech. 1995;17:848-52. http://dx.doi.org/10.1016/0141-0229(94)00120-G

23. Santayanon R, Wootthikanokkhan J. Modification of cassava starch by using propionic anhydride and properties of the starch-blended polyester polyurethane. Carbohydr Polym. 2003;51:17-24.

http://dx.doi.org/10.1016/S0144-8617(02)00109-1

24. Cael JJ, Koenig JL, Blackwell J. Infrared and Raman spectroscopy of carbohydrates. Part VI: Normal coordinate analysis of V-amylose. Biopolymers. 1975;14:1885-903. http://dx.doi.org/10.1002/bip.1975.360140909

25. Zhang L, Xie W, Zhao X, Liu Y, Gao W. Study on the morphology, crystalline structure and thermal properties of yel- 
low ginger starch acetates with different degrees of substitution. Thermochim Acta. 2009;495:57-62. http://dx.doi.org/10.1016/j.tca.2009.05.019

26. Fang JM, Fowler PA, Tomkinson J, Hill CAS. The preparation and characterisation of a series of chemically modified potato starches. Carbohydr Polym. 2002;47:245-52. http://dx.doi.org/10.1016/S0144-8617(01)00187-4

27. Sun RC, Fang JM, Tomkinson J, Geng ZC, Liu JC. Fractional isolation, physico-chemical characterization and homogeneous esterification of hemicelluloses from fast-growing poplar wood. Carbohydr Polym. 2001;44:29-39. http://dx.doi.org/10.1016/S0144-8617(00)00196-X

28. Namazi H, Fathi F, Dadkhah A. Hydrophobically modified starch using long-chain fatty acids for preparation of nanosized starch particles. Sci Iran. 2011;18:439-45. http://dx.doi.org/10.1016/j.scient.2011.05.006

29. Peng QJ, Perlin AS. Observations on N.M.R. spectra of starches in dimethyl sulfoxide, iodine-complexing, and solvation in water-di-methyl sulfoxide. Carbohydr Res. 1987; 160:57-72. http://dx.doi.org/10.1016/0008-6215(87)80303-8

30. Liebert T, Kulicke WM, Heinze T. Novel approach towards hydrolytically stable starch acetates for physiological applications. React Funct Polym. 2008;68:1-11. http://dx.doi.org/10.1016/j.reactfunctpolym.2007.10.025
31. Waigh TA, Donald AM, Heidelbach F, Riekel C, Gidley MJ. Analysis of the native structure of starch granules with small angle x-ray microfocus scattering. Biopolymers. 1999;49:91105.

http://dx.doi.org/10.1002/(SICI)1097-0282(199901)49:1<91: :AID-BIP9>3.0.CO;2-9

32. Zobel HF. Molecules to granules: a comprehensive starch review. Starch. 1988;40:44-50. http://dx.doi.org/10.1002/star.19880400203

33. Yousif EI, Gadallah MGE, Sorour AM. Physico-chemical and rheological properties of modified corn starches and its effect on noodle quality. Ann. Agric. Sci. 2012;57:19-27. http://dx.doi.org/10.1016/j.aoas.2012.03.008

34. Lawal OS. Composition, physicochemical properties and retrogradation characteristics of native, oxidised, acetylated and acid-thinned new cocoyam (Xanthosoma sagittifolium) starch. Food Chem. 2004;87:205-18.

http://dx.doi.org/10.1016/j.foodchem.2003.11.013

35. Crosbie GB. The relationship between starch swelling properties, paste viscosity and boiled noodle quality in wheat flours. J Cereal Sci. 1991;13:145-50. http://dx.doi.org/10.1016/S0733-5210(09)80031-3

36. McClements DJ. Lipid-based emulsions and emulsifiers. In: Akoh CC, Min DB, editors. Food lipids: chemistry, nutrition, and biotechnology. London, UK: CRC Press; 2008. pp. 63-97. 